\title{
Abnormal metabolic processes involved in the pathogenesis of non-alcoholic fatty liver disease (Review)
}

\author{
MINGMEI SHAO, ZIXIANG YE, YANHONG QIN and TAO WU \\ Institute of Interdisciplinary Integrative Medicine Research, \\ Shanghai University of Traditional Chinese Medicine, Shanghai 201203, P.R. China
}

Received November 26, 2019; Accepted May 28, 2020

DOI: $10.3892 /$ etm.2020.9154

\begin{abstract}
Non-alcoholic fatty liver disease (NAFLD) is one of the most common chronic liver diseases and can lead to liver cirrhosis or liver cancer in severe cases. In recent years, the incidence of NAFLD has increased substantially. The trend has continued to increase and has become a key point of concern for health systems. NAFLD is often associated with metabolic abnormalities caused by increased visceral obesity, including insulin resistance, diabetes mellitus, hypertension, dyslipidemia, atherosclerosis and systemic microinflammation. Therefore, the pathophysiological mechanisms of NAFLD must be clarified to develop new drug treatment strategies. Recently, researchers have conducted numerous studies on the pathogenesis of NAFLD and have identified various important regulatory factors and potential molecular mechanisms, providing new targets and a theoretical basis for the treatment of NAFLD. However, the pathogenesis of NAFLD is extremely complex and involves the interrelationship and influence of multiple organs and systems. Therefore,
\end{abstract}

Correspondence to: $\mathrm{Dr} \mathrm{Tao} \mathrm{Wu}$, Institute of Interdisciplinary Integrative Medicine Research, Shanghai University of Traditional Chinese Medicine, 1200 Cailun Road, Shanghai 201203, P.R. China E-mail:wutao001827@163.com

Abbreviations: AAAs, aromatic amino acids; Akt, protein kinase B; BCAAs, branched-chain amino acids; $\mathrm{Cl}^{-}$, chloride ions; ERS, endoplasmic reticulum stress; FFA, free fatty acids; FGF21, fibroblast growth factor 21; FXR, farnesoid X receptor; GLP-1, glucagon-like peptide 1; LOXL2, lysyl oxidase-like 2; LXR, liver X receptor; NAFLD, non-alcoholic fatty liver disease; NASH, non-alcoholic steatohepatitis; NPC1L1, Niemann-pick c1-like 1; HSC, hepatic stellate cells; IL-6, interleukin-6; IR, insulin resistance; IRS-1, insulin receptor substrate 1; PNPLA3, patatin-like phospholipase domain containing 3; PPAR, peroxisome proliferator-activated receptor; ROS, reactive oxygen species; SREBP, sterol regulatory element-binding protein; T2D, type 2 diabetes; TG, triglyceride; TMAO, trimethylamine-N-oxide; TNF- $\alpha$, tumor necrosis factor- $\alpha$; VLDL, very low-density lipoprotein

Key words: non-alcoholic fatty liver disease, metabolism, pathogenesis, lipid, mechanism the condition must be explored further. In the present review, the abnormal metabolic process, including glucose, lipid, amino acid, bile acid and iron metabolism are reviewed. It was concluded that NAFLD is associated with an imbalanced metabolic network that involves glucose, lipids, amino acids, bile acids and iron, and lipid metabolism is the core metabolic process. The current study aimed to provide evidence and hypotheses for research and clinical treatment of NAFLD.

\section{Contents}

1. Introduction

2. Glucose metabolism in NAFLD

3. Lipid metabolism in NAFLD

4. Amino acid metabolism in NAFLD

5. Bile acid metabolism in NAFLD

6. Iron metabolism in NAFLD

7. Conclusion

\section{Introduction}

Non-alcoholic fatty liver disease (NAFLD) is caused by excess fat deposits in the liver due to non-alcoholic factors (1), such as a high fat diet, a high cholesterol diet and a sedentary lifestyle. The condition represents a range of liver diseases from non-alcoholic fatty liver, also known as simple steatosis, to non-alcoholic steatohepatitis (NASH), fibrosis and cirrhosis $(1,2)$. NAFLD can be characterized by metabolic syndrome (MS) features, including altered glucose and lipid metabolism, imbalanced amino acid homeostasis, increased bile acid and excess hepatic iron (3). Due to the increased incidence of obesity and associated MS, NAFLD has become the most common liver disease worldwide. The global prevalence of NAFLD is currently estimated to be $25.2 \%$ (4). Notably, with the radical changes in Chinese lifestyle such as sedentary behaviour and a hypercaloric diet, the prevalence of NAFLD in China increased to 32.9\% in 2018 (5). Therefore, clarification of the pathophysiological mechanisms of NAFLD are necessary for the development of pharmacological treatment strategies.

The pathogenesis of NAFLD remains unclear and it has been widely accepted to follow the 'multiple-hit' hypothesis. 
According to this hypothesis, NAFLD is a complex disease and its pathogenesis involves diet, genetic, environment and metabolic factors that progress through different stages during the occurrence and development of NAFLD (6). Elevated levels of circulating free fatty acids (FFAs) combined with insulin resistance (IR) and excessive accumulation of triglycerides in liver cells serve a major role in the development of NAFLD (7). Additionally, lipid accumulation also responsible for oxidative stress, inflammatory response and lipotoxicity, predisposing patients to progressive liver injury (8). IR, lipotoxicity, inflammatory response, genetic polymorphisms, adipokines and intestinal flora can affect the pathogenesis of NAFLD (8). However, the interaction between these mechanisms and their changes in the occurrence and development of NAFLD remain to be determined.

Since NAFLD involves multiple metabolic pathways (Fig. 1), more attention should be paid to abnormal metabolism that may worsen metabolic disorders (9-13). In the present review, the abnormal metabolism in NAFLD, including glucose, lipid, amino acids, bile acids and iron metabolism are summarized with the aim to provide evidence and hypotheses for NAFLD diagnosis and possible therapeutic strategies.

\section{Glucose metabolism in NAFLD}

An important factor affecting NAFLD is hyperglycemia, which stimulates insulin secretion and increases triglyceride synthesis by the liver, resulting in an increase in triglycerides in the blood and gradual accumulation in the liver to form fatty liver. Prolonged and chronic hyperglycemia causes hepatocellular damage, alters the structure and function of pancreatic $\beta$ cells and causes IR, thereby inducing and accelerating the occurrence and progression of NAFLD (14).

Fructose metabolism is similar to glucose metabolism and both lead to triglyceride generation. The main difference between these processes is that glucose is primarily metabolized by glucose kinases or hexokinases, while fructose is mainly metabolized by fructose kinases (15). Fructose metabolism in the liver contributes to increased hepatic lipogenesis and inhibits mitochondrial $\beta$-oxidation of long-chain fatty acids. Numerous patients with NAFLD have insufficient antioxidant capacities to inhibit fructose metabolism (16). A recent study demonstrated that dietary fructose promoted hepatic lipogenesis via microbiota-derived acetate (17).

Insulin is closely associated with carbohydrate metabolism disorder in NAFLD as it facilitates the formation of fat and inhibits lipases, and participates in glucose homeostasis and hepatic glycogen synthesis (18). IR, an important pathophysiological basis for carbohydrate metabolism disorders, is consistent with NAFLD development. Glucagon-like peptide 1 (GLP-1) stimulates insulin secretion and suppresses glucagon in a strictly glucose-dependent manner (19). Furthermore, GLP-1 serves a role in coordination with fibroblast growth factor 21 (FGF21) (20). GLP-1 and FGF21 affect insulin function and secretion, respectively (21). Additionally, lysyl oxidase-like 2 (LOXL2) expression is directly proportional to the severity of IR and LOXL2 inhibitors can prevent NASH from progressing to fibrosis (22).

IR is a major feature of NAFLD and can lead to type 2 diabetes (T2D) and hyperinsulinemia due to glucose intolerance, which has additional effects on glucose metabolism (23). The regulatory mechanisms of IR involve chloride ions $\left(\mathrm{Cl}^{-}\right)$and insulin signaling. $\mathrm{Cl}^{-}$are common and affluent anions in living organisms. Chloride channels (ClCs) function as a type of permeable channel or protein, which are encoded and regulated by the genes of $\mathrm{ClC}$ family, $\mathrm{ClC}-2$, a member of ClCs family. Fatty deposits can be abundant by the expression of $\mathrm{ClC}-2$, which is activated by fatty acids in the liver and induces IR (24). The transduction of insulin signaling is regulated by insulin receptor substrate 1 (IRS-1) (25). When insulin binds to insulin receptors, IRS-1 is phosphorylated at tyrosine $608 / 612$ to activate the insulin signaling pathway. However, the phosphorylation of IRS-1 at serine 307/312 suppresses glucose absorption and leads to IR, which inhibits insulin signaling. Additionally, dysregulation of protein kinase B2 (Akt2) signaling pathways has been reported in NAFLD. Akt 2 facilitates glucose uptake and suppresses IR. Furthermore, Akt 2 is inhibited by fetuin-A, a type of hepatokine synthesized in the liver, which inhibits insulin receptor tyrosine phosphorylation in skeletal muscles and the activity of Akt 2 to reduce glucose uptake (26). Increasing evidence has demonstrated that disordered cellular $\mathrm{Cl}^{-}$concentrations are associated with lipid accumulation, high blood pressure and atherosclerosis $(27,28)$. Notably, chloride channel 2 (CIC-2) inhibition alleviates high fat diet-induced hepatic steatosis, inflammation and fibrosis (24).

GLP-1. GLP-1 is an antihyperglycemic hormone that induces pancreatic $\beta$ cells to secrete insulin. Trevaskis et al (29) demonstrated that GLP-1 receptor agonists significantly improve metabolism and biochemical and histopathological indicators in NASH mice. Bernsmeier et al (30) reported that patients with NAFLD exhibited IR and insufficient GLP-1 secretion. Furthermore, Chellali et al (31) demonstrated that patients with NAFLD, T2D or NAFLD+T2D generally exhibited IR and that compared with controls, plasma GLP-1 levels were obviously lower in patients with NAFLD, T2D or NAFLD+T2D. GLP-1 receptor agonists have been approved for T2D treatment and an increasing number of previous studies have demonstrated that they are also effective for NAFLD (32-35).

FGF21. FGF21 is a member of the fibroblast growth factor family and is a hormone-like endocrine factor secreted by the liver and serves a critical role in maintaining the homeostasis of glycolipid metabolism (36). Li et al (37) reported that serum FGF21 levels, such as the fatty liver index (38), which is an already known score associated with steatosis presence, have specificity for the early diagnosis of NAFLD. FGF21 is primarily produced by the liver and specifically acts on liver, fat and islet cells, FGF21 can reduce body weight, whole-body fat mass and liver triglyceride content, increases fat utilization and energy expenditure, and improves glucose tolerance and insulin sensitivity in the liver and adipose tissue (39). FGF21 is independent of insulin and regulates blood glucose and blood lipid (39). FGF21 can reduce glucose levels without triggering hypoglycemia, and increase the glucose uptake in brown fat, the browning of white fat and the increase in overall energy consumption. As a metabolic regulator, FGF21 significantly reduces the expression of key genes involved in lipid metabolism, including stearoyl-coenzyme A desaturase 1 and 


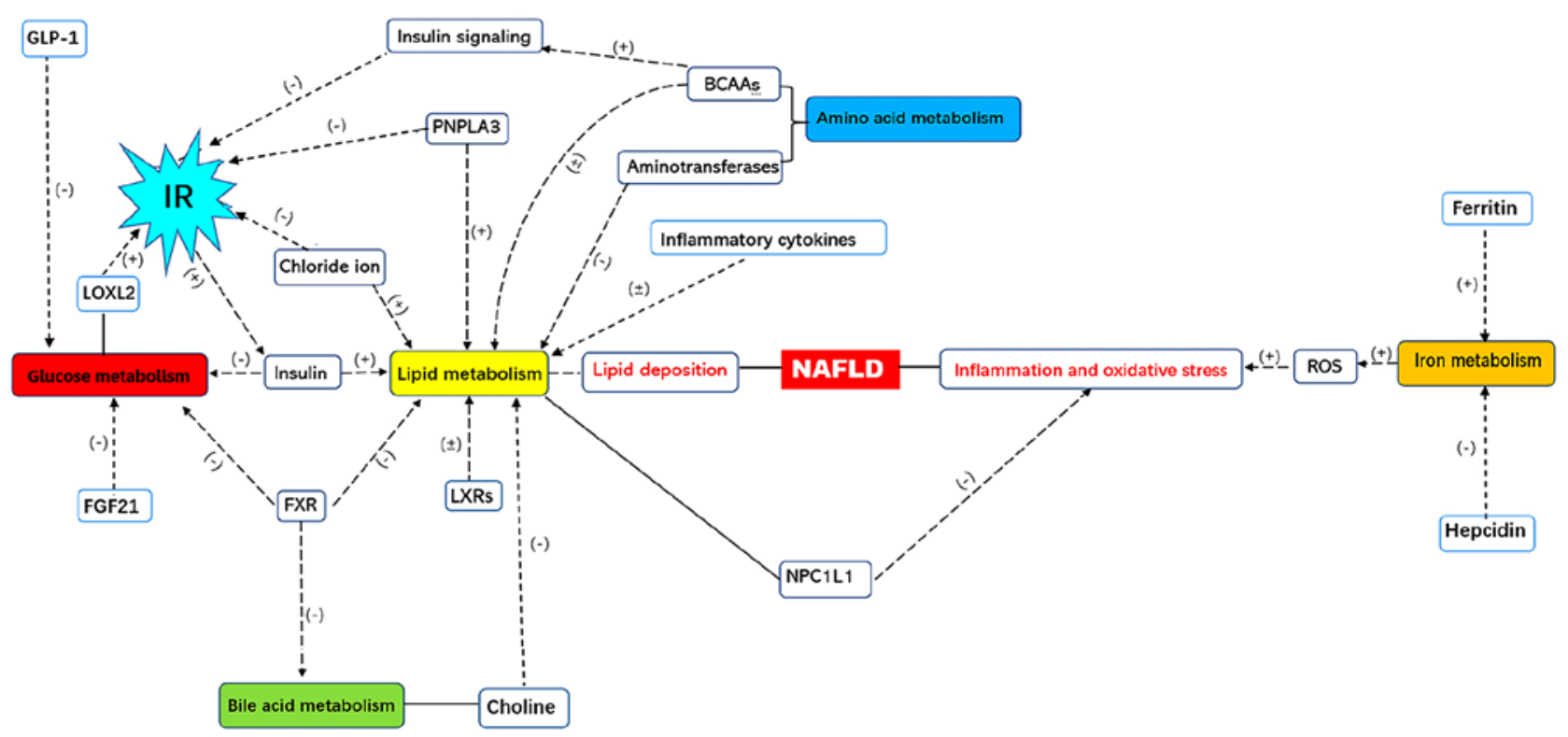

Figure 1. The metabolic network of NAFLD. NAFLD, non-alcoholic fatty liver disease; GLP-1, glucagon-like peptide 1; IR, insulin resistance; LOXL2, lysyl oxidase-like 2; FXR, farnesoid X receptor; LXRs, liver X receptors; PNPLA3, patatin-like phospholipase domain protein 3; BCAAs, branched chain amino acids; NPC1L1, Niemann-Pick c1-like 1; ROS, reactive oxygen species; (+), positive regulation; (-), negative regulation.

glucokinase, reduces fat syntheses, upregulates the expression of key genes involved in lipolysis, including leptin receptor and insulin-like growth factor binding protein 2 and promotes fat decomposition and energy metabolism, thereby reducing the accumulation of fat in liver tissue and restoring normal liver function (40).

LOXL2. IR is associated with the severity of liver fibrosis, the main determinant of NAFLD prognosis $(41,42)$. LOXL2 is an enzyme that promotes the network of collagen fibers of the extracellular matrix (43). LOXL2 expression is strongly correlated with the amount of steatosis and severity of fibrosis. Hepatic LOXL2 upregulation was specifically detected in patients with NAFLD and T2D progressing to advanced fibrosis (22). Ikenaga et al (44) reported that LOXL2 expression was virtually absent from healthy livers while strongly induced in fibrotic livers and that LOXL2 inhibition promoted fibrosis reversal. Therefore, LOXL2 antibodies are a potential treatment for liver fibrosis. A monoclonal antibody against LOXL2, simtuzumab, has been developed and is currently in phase II trials (45).

\section{Lipid metabolism in NAFLD}

NAFLD is characterized by the significant accumulation of lipids, such as triglyceride (TG), FFAs and cholesterol, in hepatocytes and serum, indicating that altered lipid metabolism is crucial in the pathogenesis of NAFLD. Excess TG and serum FFAs are common in NAFLD. Excess TG accumulate from de novo hepatic lipogenesis and the dietary fat supply, while FFAs accumulate due to lipolysis in visceral adipose tissue (46). FFAs participate in fatty acid $\beta$-oxidation, endoplasmic reticulum stress (ERS) response, lysosomal dysfunction and cell death via the mitochondrial pathway to induce NAFLD (47). Trans fatty acids (TFAs) facilitate lipogenic gene expression and hepatic lipid accumulation by causing severe steatosis and by regulating Kupffer cells (48).
There are two main pathways for lipid metabolism: The $\beta$-oxidation of liver FFAs and the binding of very low-density lipoproteins (VLDLs) in the liver $(49,50)$. When lipid synthesis pathways increase, IR develops and liver lesions are generated. However, by promoting $\beta$-oxidation and inhibiting the synthesis of lipids, IR and liver lesions can be alleviated. Additionally, certain lipids bind to VLDL and are transported out of the liver. In the smooth endoplasmic reticulum (SER), TG-rich VLDL is transfused and secreted and transported from the liver in secretory vesicles. Excessive liver lipids induce ERS via the SER and increase the production of inflammatory cytokines. Therefore, a variety of lipid metabolism-related regulatory factors are closely associated with NAFLD. However, whether these regulatory factors are an effective target for the treatment of NAFLD remains to be elucidated through further research $(51,52)$.

Inflammatory cytokines. Numerous previous studies have demonstrated that various inflammatory cytokines serve key roles in the progression of steatosis to NASH (53.54). Zahran et al (55) reported that tumor necrosis factor (TNF)- $\alpha$ levels were elevated in a patient population with NASH compared with controls. Furthermore, Bocsan et al (56) demonstrated that plasma interleukin (IL)- 6 and TNF- $\alpha$ levels were significantly higher in patients with NASH compared with controls. TNF- $\alpha$ is produced by hepatocytes and infiltrating immune cells. Moreover, it stimulates liver steatosis, which in turn increases serum TG levels (57). Additionally, TNF- $\alpha$ activates Kupffer cells, which in turn stimulate liver fibrosis during NAFLD progression (58). IL-6 is primarily secreted by adipose tissue and, as an important mediator of fatty acid metabolism, serves a paradoxical role in the liver: While the hepatic IL-6 signaling pathway has a protective effect against the development of liver steatosis, it may also promote liver inflammation (59). 
Patatin-like phospholipase domain containing 3 (PNPLA3). PNPLA3 is a secretory adipose factor that is widely expressed in human tissues, particularly in liver and adipose tissues (60). In 2008, Romeo et al (61) conducted a genome-wide association analysis to screen for pathogenic genes in NAFLD. A group of nonsynonymous sequence variations including Hispanic, African-American and European-American participants $(n=9.229)$ were selected and polymorphic PNPLA3 rs738409 in liver tissue was identified in order to identify genetic variants contributing to differences in hepatic fat content. Increased concentrations of fat and liver inflammation were highly associated with Homeostatic Model Assessment of IR and the mechanism of liver damage may be associated with intrahepatic lipid deposition. Additionally, Wang et al (62) studied 768 patients from the Han Chinese population and confirmed the association between PNPLA3 rs738409 and an increased risk for NAFLD in this population, emphasizing its effects on NAFLD among multiple ethnic groups. Several previous studies in a meta-analysis demonstrated that genetic variation in PNPLA3 increases the risk of NAFLD in European and Chinese populations (63). Numerous previous studies have reported that PNPLA3 gene polymorphism is associated with an increase in liver fat content and liver inflammation (63-65). As an enzyme with a bidirectional ability to regulate fat metabolism, PNPLA3 promotes lipid synthesis and may be involved in ectopic lipid deposition and IR, the two key factors in the pathogenesis of NAFLD; therefore, PNPLA3 leads to the pathogenesis of NAFLD (66).

Peroxisome proliferator-activated receptors (PPARs). PPAR ligand-activated transcription factors control different aspects of lipid catabolism. The PPAR subtype PPAR- $\alpha$ is highly expressed in the liver, where it promotes genes that regulate the $\beta$-oxidation of fatty acids. Thus, inducing PPAR- $\alpha$-regulated lipid catabolic pathway genes may enhance NAFLD. Another subtype, PPAR- $\gamma$, is a nuclear receptor that regulates insulin sensitivity and lipid metabolism, and a molecular target for insulin sensitizing agents. PPAR- $\gamma$ is expressed in hepatic stellate cells (HSCs) to influence perilipin expression, which regulates lipid droplet metabolism. The activation of HSCs largely contributes to the fibrogenesis process (67).

Sterol regulatory element-binding proteins (SREBPs). SREBPs control cholesterol, TGs and fatty acids. SREBP-1c is a subtype predominantly localized in the adult liver and is required for simple steatosis during fasting. Overexpressed SREBP-1c leads to excessive TG accumulation in the liver and ultimately to NAFLD. Thus, the inhibition of SREBP-1c is a preventive approach (68). PPAR $\alpha$ and SREBP-1 are key determinants of NAFLD (69).

SREBP-2 is an important nuclear transcription factor that regulates cellular cholesterol homeostasis. Its activation promotes the accumulation of hepatocyte cholesterol by facilitating cholesterol synthesis and uptake and suppressing reverse cholesterol transport (70). Additionally, SREBP-2 predicts NASH and widely impairs pancreatic $\beta$ cell function, tissue insulin sensitivity and adipokine and lipoprotein responses to fat uptake. Thus, elevated SREBP-2 increases the prevalence of NAFLD and cardiovascular diseases. Abnormal SREBP-2 activation can be reversed by depleting cholesterol in adipocytes (71).
Adiponectin. Adiponectin, an insulin-sensitizing adipocytokine, is an adipocyte-derived anti-inflammatory mediator that acts via two receptors that elicit AMP kinase signaling (72). Adipose tissue is a major site of endogenous adiponectin production. Previous research has demonstrated that plasma levels of adiponectin are significantly diminished in visceral obesity and states of IR such as NASH, T2D and atherosclerosis $(73,74)$. Adiponectin and its agonists may represent potential alternative therapeutic approaches for NAFLD treatment.

Leptin. Leptin is a hormone secreted mainly by the adipocytes in white adipose tissue and is a product of the obese gene (75). Perfield et al (76) reported that de novo lipogenesis was induced and that hepatic mitochondria were reduced and inhibited in leptin-deficient NAFLD mice. Zelber-Sagi et al (77) demonstrated that leptin levels were significantly higher in patients with NAFLD compared with patients without NAFLD at 7 years of follow-up. Furthermore, Polyzos et al (78) revealed that serum leptin levels in patients with NAFLD were higher compared with controls and that serum leptin levels were associated with increased severity of NAFLD. However, while a lack of leptin may lead to liver steatosis, which can be reversed by leptin replacements (79), excessive leptin may cause liver inflammation and fibrosis.

Liver $X$ receptors (LXRs). As members of the metabolic nuclear receptor superfamily, LXRs influence the regulation of cholesterol absorption, conveyance, transportation and excretion (80). Research has demonstrated that LXR activation regulates cholesterol homeostasis, induces anti-inflammatory effects and increases insulin sensitivity (81). Inhibiting liver LXR transcriptional activity in NAFLD effectively reduces liver steatosis, inflammation and fibrosis. However, research has found that LXR is highly expressed in the livers of patients with NAFLD and increases with the severity of NAFLD. LXR expression is directly proportional to liver lipid deposition (82). However, the uncertainty about whether LXR activation or inhibition is beneficial for NAFLD treatment has hindered the development of LXR-related drugs (83).

Plin2. Plin2, also known as adipophilin or adipose differentiation-related protein, is commonly reported on the surface of lipid droplets in most tissues and hepatic lipids effectively induce Plin2 expression. Plin2 inhibition increases insulin sensitivity and reduces fatty liver (84). While perilipin 2-antisense oligonucleotide (Plin2-ASO) treatment decreases steatosis, it also promotes proliferation and fibrosis. Furthermore, Plin2-ASO inhibits the expression of genes that participate in TG biosynthesis and utilization, including diacylglycerol O-acyltransferase 2, acetyl coenzyme A carboxylase and fatty acid oxidation carnitine palmitoyltransferase 1 by suppressing transcription factors. Additionally, Plin2-ASO therapy significantly decreases the expression of genes related to cholesterol and steroid metabolism, reduces hepatic VLDL secretion and increase insulin sensitivity (85).

Choline. Choline is an important phospholipid component present in cell membranes and is ingested exogenously and synthesized endogenously. Choline is one of the methyl donors 
for the synthesis of phosphatidylcholine in the liver, which is required for the synthesis and secretion of VLDL. Therefore, choline serves a vital role in liver lipid transport (86). Choline has a negative correlation with NAFLD development by affecting intracellular lipid metabolism and muscle membrane lipid composition (87). Dietary choline is metabolized by intestinal microbiota and converted to trimethylamine, resulting in choline deficiency in the liver. Choline deficiency hinders the synthesis and secretion of VLDL, leads to the accumulation of TG in the liver and promotes the onset of NAFLD. High-fat diets lead to the formation of intestinal microbiota that convert dietary choline into methylamines, reducing circulating plasma levels of phosphatidylcholine to produce similar effects of choline-deficient diets and causing NASH (88). Choline-deficient diets have been used to establish animal models of NASH (89).

\section{Amino acid metabolism in NAFLD}

Impaired liver function leads to an imbalance in amino acid homeostasis. Amino acid metabolism is extensively altered in NAFLD, involving branched-chain amino acids (BCAAs), aromatic amino acids (AAAs), methionine, homocysteine and arginine. Additionally, fatty liver is associated with deregulated liver expression of aminotransferases (90). The profiles of amino acid metabolism gene sets can be used to evaluate hepatic oxidative stress in patients with NAFLD (91).

BCAAs. BCAAs are amino acids with nonlinear aliphatic side-chains and include the essential amino acids leucine, valine and isoleucine. Cheng et al (92) reported increased serum BCAAs in patients with NAFLD. Lake et al (91) demonstrated that during the progression of steatosis to $\mathrm{NASH}$, serum leucine, isoleucine and valine levels were significantly increased. This increase is associated with liver fat accumulation during the early stages of NAFLD. BCAAs mediate numerous biological functions in NAFLD. Firstly, BCAAs regulate glucose metabolism by inducing insulin signaling $(93,94)$. Secondly, they increase lipolysis and hyperlipidemia, which cause hepatic lipotoxicity that leads to inhibited autophagy in hepatocytes (95). Thirdly, BCAAs are beneficial for treating cirrhosis by decreasing portal vein pressure and increasing mean artery pressure (96). Finally, BCAAs induce higher branched-chain $\alpha$-keto acid dehydrogenase E1 $\alpha$ expression levels in skeletal muscles, which facilitates BCAA metabolism in muscle tissue (97).

Leucine supplementation has been demonstrated to activate mammalian target of rapamycin, which mediates cellular proliferation and protein synthesis, and increases insulin sensitivity. However, while leucine alleviates T2D, it also exacerbates NAFLD, making it difficult to use in NAFLD treatment (98).

$A A A s$. AAAs are a class of $\alpha$-amino acids that have aromatic rings and include tryptophan, phenylalanine and tyrosine. Celinski et al (99) demonstrated that tryptophan substantially attenuated the levels of proinflammatory cytokines and improved certain parameters ( $\gamma$-glutamyl transferase, triglyceride and low-density lipoprotein) of lipid metabolism in patients with NAFLD. Chen et al (100) reported that serum phenylalanine concentration was two-fold higher in patients with NAFLD compared with controls. Furthermore, Jin et al (101) investigated the metabolic pathways that were altered in association with hepatic steatosis in adolescents and demonstrated that plasma tyrosine levels were positively correlated with the severity of liver steatosis. Phenylalanine is catalyzed to tyrosine by phenylalanine hydroxylase in the liver, where it is further metabolized (102). Presently, the mechanism of AAA metabolic disorders in NAFLD remains unclear. A possible explanation may be that tyrosine enters the ketogenic pathway and is directly degraded to acetyl coenzyme A via ketogenic action (101). Therefore, increased phenylalanine and tyrosine intake may contribute to fat deposition in the liver.

Methionine and homocysteine. Methionine is an essential sulfur-containing amino acid that is mainly metabolized in the liver (103). Homocysteine is a sulfhydryl-containing amino acid produced and catabolized primarily in the liver and increased homocysteine concentrations in the event of liver injury. Alternatively, elevated homocysteine may conversely promote the progression of liver damage (104). Both methionine and homocysteine are associated with NAFLD. Methionine metabolism impacts the methylation process that leads to the production of glutathione and methylarginines, and regulates homocysteine concentrations. However, methionine deficiency leads to impaired methyltransferase and antioxidative reactions, and elevated homocysteine (105). Increased homocysteine causes hyperhomocysteinemia, which alters intracellular lipid metabolism to facilitate fat accumulation (106).

Arginine. Arginine has antioxidant effects on NASH by inhibiting cytochrome P450 family 2 subfamily E member 1 activity and by decreasing TNF- $\alpha$ and antioxidant enzyme concentrations (107). Dogru et al (108) reported that increased circulating asymmetric dimethylarginine may be used as an early marker for NAFLD. Additionally, Voloshin et al (109) synthesized a novel chenodeoxycholic acid-arginine ethyl ester conjugate that may be used to treat NAFLD. The conjugate reduces liver steatosis by decreasing cholesterol and blood glucose.

Aminotransferases. Aminotransferases are barometers of liver health as they transport excessive amino acids into the circulation to manage liver metabolic derangement associated with severe gluconeogenesis and IR (90). Aspartate aminotransferase, alanine transaminase and $\gamma$-glutamyltransferase are generally elevated in NAFLD and are positively associated with CIC-2 expression in the liver $(24,110)$.

\section{Bile acid metabolism in NAFLD}

Bile acid is an essential regulator of hepatic fat and glucose metabolism. The concentration of certain serum bile acids increase during the progression of NAFLD, including hydrophobic and cytotoxic bile acids, such as taurodeoxycholic acid and taurocholic acid, respectively (111). Bile acid metabolism is obliterated in NAFLD, likely due to increased hepatic inflammatory signaling (112). Furthermore, increased bile acid levels are associated with altered hepatic transport protein 
multidrug resistance protein 3 expression in NAFLD (113). The increased transcription of bile acid synthesis pathway enzymes (including sterol 12 $\alpha$-hydroxylase, bile acid-CoA:amino acid $\mathrm{N}$-acyltransferase and 25-hydroxycholesterol-7 $\alpha$-hydroxylase) indicates that the liver attempts to ameliorate hepatotoxicity during the progression of NAFLD (114).

Farnesoid X receptor $(F X R)$. Nuclear receptors (NRs) are transcriptional factors sensitive to environmental or hormonal signals (115). The expression of NRs, such as FXR, have a negative correlation with NAFLD severity at the transcriptional level (116). Schiöth et al (117) reported that additional NAFLD-induced modulating effects on type 2 diabetes were associated with altered composition and concentrations of bile acids, which have a continuous effect on FXR-dependent regulatory pathways.

FXRs are abundantly expressed in the liver and their upregulation controls glucose, lipid, cholesterol and bile acid homeostasis and inflammation to reduce NAFLD. Firstly, FXRs inhibit hepatic gluconeogenesis and peripheral insulin sensitivity to reduce plasma glucose concentrations. Secondly, FXRs suppress bile acid synthesis by inhibiting cholesterol 7 $\alpha$-hydroxylase (CYP7A1), the rate-limiting enzyme for the synthesis of bile acids from cholesterol (118). The interaction between bile acids and FXRs leads to a reduction in triglyceride concentrations in plasma and, as a consequence, inhibits hepatic lipid deposition (119).

Niemann-pick cl-like 1 (NPC1L1). NPC1L1, which reabsorbs cholesterol from bile and transports it to the liver, is expressed on the bile duct membrane and is an aggravating factor of NAFLD (120). NAFLD often exhibits oxidative stress, which leads to increased free-radical activity and lipid peroxidation by increasing reactive oxygen species (ROS). ROS facilitate the peroxidation of lipids, induction of cytokines, chemoattraction of inflammatory cells and HSC activation, and ultimately cause fibrosis with extracellular matrix deposition (1). NPC1L1 resists oxidative stress and endoplasmic reticulum stress (ERS) by transporting free cholesterol in hepatic cells and modulating intracellular cholesterol content, particularly in mitochondria and the endoplasmic reticulum (121). Inhibiting NPC1L1 eventually reduces cholesterol uptake and induces the recovery of key molecules involved in insulin signaling, including Akt phosphorylation and gluconeogenic enzymes (122).

Bile acid transporters. Bile acid transporters are associated with the progression of NAFLD (123). $\mathrm{Na}^{+}$-taurocholate cotransporting polypeptide (NTCP), an influx bile acid transporter, participates in the reabsorption of bile acids (124). As a bile salt export pump, NTCP is an effluent bile acid transporter that exports bile acids. Thus, the upregulation of NTCP causes excessive bile acid concentrations in hepatocytes, which ultimately leads to cell injury (116). Therefore, blocking apical sodium-dependent bile acid transporter function improves NAFLD (125).

Intestinal flora. Intestinal ecological disruption in NAFLD has been fully documented (126-128). Intestinal flora mediates the detoxification of bile acids and the conversion of primary bile acid to secondary bile acid species, including lithocholic acid (LCA) and deoxycholic acid. Therefore, inhibiting intestinal microbiota increases hepatic binding to secondary bile acids, which leads to the increased burden of the secondary bile acid system and possible toxic effects. Vitamin D attenuates the toxic effects of LCA and may be a biomarker for the noninvasive diagnosis of NAFLD progression (126-128).

Trimethylamine-N-oxide (TMAO) is a gut-flora-dependent metabolite of choline. Chen et al (129) demonstrated that the increased risk of fatty liver disease may be caused by TMAO due to its effect of decreasing the total bile acid levels via two pathways: By decreasing the synthesis of bile acids via the inhibition of key enzyme CYP7A1 or by limiting the enterohepatic circulation of bile acids between the liver and intestines by decreasing organic anion transporter and multidrug resistance protein family protein expression (130). Therefore, TMAO may possibly affect hepatic TG levels and reverse the direction of cholesterol transport and glucose and energy homeostasis by altering the synthesis and transport of bile acids, indicating that it is a potential risk factor for fatty liver disease (129).

\section{Iron metabolism in NAFLD}

A total of $\sim 30 \%$ of patients with NAFLD exhibit signs of iron metabolism disorders (131). Iron metabolism disorders in NAFLD are commonly associated with excess hepatic iron and deficient serum iron, and NASH livers exhibit decreased transferrin and transferrin receptor $2(132,133)$. High dietary iron intake is a risk factor for NAFLD. Excess dietary iron leads to hepatic oxidative stress, inflammation and hepatocellular ballooning injury, which ultimately causes NASH (134). Moreover, hepatic iron accumulation increases hepatic cholesterol synthesis, lipid deposition and impaired hepatic cellular stress responses, which exacerbate NAFLD $(135,136)$. Iron serves a substantial role in the occurrence of oxidative stress as it is a catalyst for ROS generation (137). Oxidative stress often impairs mitochondrial function, which predisposes individuals to impaired fatty acid oxidation and eventually leads to steatosis and necrotizing inflammation through various cytokines, such as TNF- $\alpha$, IL-6 and IL-8, malondialdehyde and nitric oxide (138). Furthermore, ROS induces transferrin to decrease iron absorption and interact with iron to induce IR by inhibiting carbohydrate consumption, altering the function of adipose tissue and impacting the release of adipokines $(132,137)$. In NAFLD, hepatic iron accumulation is associated with ferritin, hepcidin and human hemochromatosis protein by impacting iron export and import from hepatocytes $(131,139)$.

Ferritin. Ferritin is the primary iron-storage protein in the majority tissues such as in the liver and brain, and increased expression of ferritin indicates iron overload in tissues and circulation. Patients with high ferritin have more severe NASH and advanced fibrosis compared with patients with normal ferritin $(140,141)$. Ferritin can be decreased by restricted calorie and iron intake (142). Serum ferritin concentrations are commonly elevated in patients with NAFLD due to increased iron stores, fat content, oxidative stress, ERS, systemic inflammation and genetic background $(143,144)$. 
Hepcidin. Hepcidin is the main iron-regulating peptide (145). Decreased hepcidin expression is frequently observed in patients with NAFLD and is considered to be a cause of hepatic iron overload (146). Furthermore, hepcidin suppresses iron influx from diets and efflux from macrophages by inhibiting ferroportin, determining oxidative stress and driving transformation of macrophages into foam cells (147).

\section{Conclusion}

In summary, NAFLD is associated with an imbalanced metabolic network that involves glucose, lipids, amino acids, bile acids and iron. Among the participating mechanisms underlying NAFLD, lipid metabolism is the core metabolic process. Lipid metabolism disorders directly lead to lipid deposits. Glucose is linked to lipids by insulin, which is abundant but inefficiently processed in NAFLD. NAFLD often exhibits hyperinsulinemia and IR, which lead to excess TG accumulation and T2D, respectively. Additionally, amino acids simultaneously regulate glucose and lipid metabolism. Bile acid is associated with glucose and lipids through FXRs and choline. Furthermore, iron metabolism is a unique pathway and iron accumulation induces ROS to participate in inflammation and oxidative stress. Oxidative stress also increases lipid accumulation by adding fatty acids and cholesterol, and is regulated by NPC1L1.

Metabolism during NAFLD pathogenesis is very complex and the metabolic processes are not independent; rather, they mutually contribute and influence each other. However, previous studies mainly focus on the pathogenesis of NAFLD from a single perspective, facilitating the separation of factors that were originally interrelated. It is challenging to conduct systematic, integrated and relevant studies or draw corresponding conclusions. Therefore, an investigation and exploration of the detailed mechanism of the pathogenesis of NAFLD is necessary.

Given the complex pathogenesis of NAFLD, a single treatment for all patients with NAFLD may not be discovered. In the future, personalized treatment may be an effective therapy for NAFLD. With additional in-depth studies on its pathogenesis, NAFLD may be effectively prevented and treated in the future.

\section{Acknowledgements}

Not applicable.

\section{Funding}

The current study was supported by the National Natural Science Foundation of China (grant no. 81873076) and Shanghai Talents Development Fund Project (grant no. 2017090).

\section{Availability of data and materials}

Not applicable.

\section{Authors' contributions}

MS wrote the manuscript. MS, ZY, YQ and TW conducted research on the pathogenesis of NAFLD. TW supervised and revised the manuscript.

\section{Ethics approval and consent to participate}

Not applicable.

\section{Patient consent for publication}

Not applicable.

\section{Competing interests}

The authors declare that they have no competing interests.

\section{References}

1. Vanni E, Bugianesi E, Kotronen A, De Minicis S, Yki-Järvinen H and Svegliati-Baroni G: From the metabolic syndrome to NAFLD or vice versa? Dig Liver Dis 42: 320-330, 2010.

2. Rinella ME: Nonalcoholic fatty liver disease: A systematic review. JAMA 313: 2263-2273, 2015.

3. Gawrieh S, Marion MC, Komorowski R, Wallace J, Charlton M, Kissebah A, Langefeld CD and Olivier M: Genetic variation in the peroxisome proliferator activated receptor-gamma gene is associated with histologically advanced NAFLD. Dig Dis Sci 57: 952-957, 2012.

4. Younossi ZM, Koenig AB, Abdelatif D, Fazel Y, Henry L and Wymer M: Global epidemiology of nonalcoholic fatty liver disease-meta-analytic assessment of prevalence, incidence, and outcomes. Hepatology 64: 73-84, 2016.

5. Zhou J, Zhou F, Wang W, Zhang XJ, Ji YX, Zhang P, She ZG, Zhu L, Cai J and Li H: Epidemiological feature of NAFLD from 1999 to 2018 in China. Hepatology 71: 1851-1864, 2020.

6. Marchisello S, Di Pino A, Scicali R, Urbano F, Piro S, Purrello F and Rabuazzo AM: Pathophysiological, molecular and therapeutic issues of nonalcoholic fatty liver disease: An overview. Int J Mol Sci 20: 1948, 2019.

7. Bessone F, Razori MV and Roma MG: Molecular pathways of nonalcoholic fatty liver disease development and progression. Cell Mol Life Sci 76: 99-128, 2019.

8. Wasilewska N, Bobrus-Chociej A, Harasim-Symbor E, Tarasów E Wojtkowska M, Chabowski A and Lebensztejn DM: Increased serum concentration of ceramides in obese children with nonalcoholic fatty liver disease. Lipids Health Dis 17: 216, 2018.

9. Jegatheesan P and De Bandt JP: Fructose and NAFLD: The multifaceted aspects of fructose metabolism. Nutrients 9: 230, 2017.

10. Chen L, Chen XW, Huang X, Song BL, Wang Y and Wang Y: Regulation of glucose and lipid metabolism in health and disease. Sci China Life Sci 62: 1420-1458, 2019.

11. Kim SH, Kwon DY, Kwak JH, Lee S, Lee YH, Yun J, Son TG and Jung YS: Tunicamycin-induced ER stress is accompanied with oxidative stress via abrogation of sulfur amino acids metabolism in the liver. Int J Mol Sci 19: 4114, 2018.

12. Mouzaki M, Wang AY, Bandsma R, Comelli EM, Arendt BM, Zhang L, Fang S, Fischer SE, McGilvray LG and Allard JP: Bile acids and dysbiosis in non-alcoholic fatty liver disease. PLoS One 11: e0151829, 2016.

13. Xu J, Sun W and Yang L: Association between iron metabolism and cognitive impairment in older non-alcoholic fatty liver disease individuals: A cross-sectional study in patients from a Chinese center. Medicine (Baltimore) 98: e18189, 2019.

14. Lim JS, Mietus-Snyder M, Valente A, Schwarz JM and Lustig RH: The role of fructose in the pathogenesis of NAFLD and the metabolic syndrome. Nat Rev Gastroenterol Hepatol 7: 251-264, 2010.

15. Jensen T, Abdelmalek MF, Sullivan S, Nadeau KJ, Green M, Roncal C, Nakagawa T, Kuwabara M, Sato Y, Kang DH, et al: Fructose and sugar: A major mediator of non-alcoholic fatty liver disease. J Hepatol 68: 1063-1075, 2018.

16. Alwahsh SM and Gebhardt R: Dietary fructose as a risk factor for non-alcoholic fatty liver disease (NAFLD). Arch Toxicol 91: 1545-1563, 2017.

17. Zhao S, Jang C, Liu J, Uehara K, Gilbert M, Izzo L, Zeng X, Trefely S, Fernandez S, Carrer A, et al: Dietary fructose feeds hepatic lipogenesis via microbiota-derived acetate. Nature 579: 586-591, 2020. 
18. Zhang S, Du T, Zhang J,Lu H, Lin X, Xie J, Yang Y and Yu X: The triglyceride and glucose index (TyG) is an effective biomarker to identify nonalcoholic fatty liver disease. Lipids Health Dis 16 15, 2017.

19. Khan RS, Bril F, Cusi K and Newsome PN: Modulation of insulin resistance in nonalcoholic fatty liver disease. Hepatology 70: 711-724, 2019.

20. Omar BA, Andersen B, Hald J, Raun K, Nishimura Eand Ahrén B: Fibroblast growth factor 21 (FGF21) and glucagon-like peptide 1 contribute to diabetes resistance in glucagon receptor-deficient mice. Diabetes 63: 101-110, 2014.

21. Patel V, Joharapurkar A, Kshirsagar S, Sutariya B, Patel M, Patel H, Pandey D, Patel D, Ranvir R, Kadam S, et al: Coagonist of GLP-1 and glucagon receptor ameliorates development of non-alcoholic fatty liver disease. Cardiovasc Hematol Agents Med Chem 16: 35-43, 2018.

22. Dongiovanni P, Meroni M, Baselli GA, Bassani GA, Rametta R, Pietrelli A, Maggioni M, Facciotti F, Trunzo V, Badiali S, et al: Insulin resistance promotes lysyl oxidase like 2 induction and fibrosis accumulation in non-alcoholic fatty liver disease. Clin Sci (Lond) 131: 1301-1315, 2017.

23. Uygun A, Kadayifci A, Demirci H, Saglam M, Sakin YS, Ozturk K, Polat Z, Karslioglu Y and Bolu E: The effect of fatty pancreas on serum glucose parameters in patients with nonalcoholic steatohepatitis. Eur J Intern Med 26: 37-41, 2015.

24. Fu D, Cui $\mathrm{H}$ and Zhang Y: Lack of ClC-2 alleviates high fat diet-induced insulin resistance and non-alcoholic fatty liver disease. Cell Physiol Biochem 45: 2187-2198, 2018.

25. Kumashiro N, Erion DM, Zhang D, Kahn M, Beddow SA, Chu X, Still CD, Gerhard GS, Han X, Dziura J, et al: Cellular mechanism of insulin resistance in nonalcoholic fatty liver disease. Proc Natl Acad Sci USA 108: 16381-16385, 2011.

26. Wu W, Bi Y, Tangsun Y, Yin W, Chen Y and Zhu D: Effects of transcription factor sterol regulatory element binding protein-1c in palmitate acid-induced L6 cells insulin resistance and its mechanism. Zhonghua Yi Xue Za Zhi 95: 611-615, 2015 (In Chinese).

27. Nakajima K, Oda E and Kanda E: The association of serum sodium and chloride levels with blood pressure and estimated glomerular filtration rate. Blood Press 25: 51-57, 2016.

28. Hong L, Xie ZZ, Du YH, Tang YB, Tao J, Lv XF, Zhou JG and Guan YY: Alteration of volume-regulated chloride channel during macrophage-derived foam cell formation in atherosclerosis. Atherosclerosis 216: 59-66, 2011.

29. Trevaskis JL, Griffin PS, Wittmer C, Neuschwander-Tetri BA Brunt EM, Dolman CS, Erickson MR, Napora J, Parkes DG and Roth JD: Glucagon-like peptide-1 receptor agonism improves metabolic, biochemical, and histopathological indices of nonalcoholic steatohepatitis in mice. Am J Physiol Gastrointest Liver Physiol 302: G762-G772, 2012

30. Bernsmeier C, Meyer-Gerspach AC, Blaser LS, Jeker L, Steinert RE, Heim MH and Beglinger C: Glucose-induced glucagon-like Peptide 1 secretion is deficient in patients with non-alcoholic fatty liver disease. PLoS One 9: e87488, 2014.

31. Chellali S, Boudiba A, Griene L and Koceir EA: Incretinsadipocytokines interactions in type 2 diabetic subjects with or without non-alcoholic fatty liver disease: Interest of GLP-1 (glucagon-like peptide-1) as a modulating biomarker. Ann Biol Clin (Paris) 77: 261-271, 2019

32. Thompson AM and Trujillo JM: Dulaglutide: The newest GLP-1 receptor agonist for the management of type 2 diabetes. Ann Pharmacother 49: 351-359, 2015.

33. Knop FK, Brønden A and Vilsbøll T: Exenatide: Pharmacokinetics, clinical use, and future directions. Expert Opin Pharmacother 18: 555-571, 2017

34. Dong Y, Lv Q, Li S, Wu Y, Li L, Li J, Zhang F, Sun X and Tong N: Efficacy and safety of glucagon-like peptide-1 receptor agonists in non-alcoholic fatty liver disease: A systematic review and meta-analysis. Clin Res Hepatol Gastroenterol 41: 284-295, 2017.

35. Petit JM and Vergès B: GLP-1 receptor agonists in NAFLD. Diabetes Metab 43 (Suppl 1): 2S28-2S33, 2017.

36. Ye DW, Rong XL, Xu AM and Guo J: Liver-adipose tissue crosstalk: A key player in the pathogenesis of glucolipid metabolic disease. Chin J Integr Med 23: 410-414, 2017.

37. Li H, Dong K, Fang Q, Hou X, Zhou M, Bao Y, Xiang K, Xu A and Jia W: High serum level of fibroblast growth factor 21 is an independent predictor of non-alcoholic fatty liver disease: A 3-year prospective study in China. J Hepatol 58: 557-563, 2013

38. Zhou K and Cen J: The fatty liver index (FLI) and incident hypertension: A longitudinal study among Chinese population. Lipids Health Dis 17: 214, 2018.
39. Emanuelli B, Vienberg SG, Smyth G, Cheng C, Stanford KI, Arumugam M, Michael MD, Adams AC, Kharitonenkov A and Kahn CR: Interplay between FGF21 and insulin action in the liver regulates metabolism. J Clin Invest 124: 515-527, 2014.

40. Tucker B, Li H, Long X, Rye KA and Ong KL: Fibroblast growth factor 21 in non-alcoholic fatty liver disease. Metabolism 101: 153994,2019

41. Dongiovanni P, Rametta R, Meroni M and Valenti L: The role of insulin resistance in nonalcoholic steatohepatitis and liver disease development-a potential therapeutic target? Expert Rev Gastroenterol Hepatol 10: 229-242, 2016.

42. Angulo P, Kleiner DE, Dam-Larsen S, Adams LA, Bjornsson ES, Charatcharoenwitthaya P, Mills PR, Keach JC, Lafferty HD, Stahler A, et al: Liver fibrosis, but no other histologic features, is associated with long-term outcomes of patients with nonalcoholic fatty liver disease. Gastroenterology 149: 389-397.e10, 2015.

43. Grau-Bové X, Ruiz-Trillo I and Rodriguez-Pascual F: Origin and evolution of lysyl oxidases. Sci Rep 5: 10568, 2015.

44. Ikenaga N, Peng ZW, Vaid KA, Liu SB, Yoshida S, Sverdlov DY, Mikels-Vigdal A, Smith V, Schuppan D and Popov YV: Selective targeting of lysyl oxidase-like 2 (LOXL2) suppresses hepatic fibrosis progression and accelerates its reversal. Gut 66: 1697-1708, 2017.

45. Williamson KD and Chapman RW: New therapeutic strategies for primary sclerosing cholangitis. Semin Liver Dis 36: 5-14, 2016.

46. Ibrahim SH, Kohli R and Gores GJ: Mechanisms of lipotoxicity in NAFLD and clinical implications. J Pediatr Gastroenterol Nutr 53: 131-140, 2011.

47. Ferramosca A and Zara V: Modulation of hepatic steatosis by dietary fatty acids. World J Gastroenterol 20: 1746-1755, 2014.

48. Obara N, Fukushima K, Ueno Y, Wakui Y, Kimura O, Tamai K, Kakazu E, Inoue J, Kondo Y, Ogawa N, et al: Possible involvement and the mechanisms of excess trans-fatty acid consumption in severe NAFLD in mice. J Hepatol 53: 326-334, 2010.

49. Dongiovanni P, Anstee QM and Valenti L: Genetic predisposition in NAFLD and NASH: Impact on severity of liver disease and response to treatment. Curr Pharm Des 19: 5219-5238, 2013.

50. Orellana-Gavaldà JM, Herrero L, Malandrino MI, Pañeda A, Sol Rodríguez-Peña M, Petry H, Asins G, Van Deventer S, Hegardt FG and Serra D: Molecular therapy for obesity and diabetes based on a long-term increase in hepatic fatty-acid oxidation. Hepatology 53: 821-832, 2011.

51. Gastaldelli A: Insulin resistance and reduced metabolic flexibility: Cause or consequence of NAFLD? Clin Sci (Lond) 131: 2701-2704, 2017.

52. Poulsen MK, Nellemann B, Bibby BM, Stødkilde-Jørgensen H, Pedersen SB, Grønbaek H and Nielsen S: No effect of resveratrol on VLDL-TG kinetics and insulin sensitivity in obese men with nonalcoholic fatty liver disease. Diabetes Obes Metab 20: 2504-2509, 2018

53. Assunção SNF, Sorte NCAB, Alves CAD, Mendes PSA, Alves CRB and Silva LR: Inflammatory cytokines and non-alcoholic fatty liver disease (NAFLD) in obese children and adolescents. Nutr Hosp 35: 78-83, 2018.

54. Lopetuso LR, Mocci G, Marzo M, D'Aversa F, Rapaccini GL, Guidi L, Armuzzi A, Gasbarrini A and Papa A: Harmful effects and potential benefits of anti-tumor necrosis factor (TNF)- $\alpha$ on the liver. Int J Mol Sci 19: 2199, 2018.

55. Zahran WE, Salah El-Dien KA, Kamel PG and El-Sawaby AS: Efficacy of tumor necrosis factor and interleukin-10 analysis in the follow-up of nonalcoholic fatty liver disease progression. Indian J Clin Biochem 28: 141-146, 2013.

56. Bocsan IC, Milaciu MV, Pop RM, Vesa SC, Ciumarnean L, Matei DM and Buzoianu AD: Cytokines genotype-phenotype correlation in nonalcoholic steatohepatitis. Oxid Med Cell Longev 2017: 4297206, 2017.

57. Yang R, Guan MJ, Zhao N, Li MJ and Zeng T: Roles of extrahepatic lipolysis and the disturbance of hepatic fatty acid metabolism in TNF- $\alpha$-induced hepatic steatosis. Toxicology 411: 172-180, 2019

58. Jorge ASB, Andrade JMO, Paraíso AF, Jorge GCB, Silveira CM, de Souza LR, Santos EP, Guimaraes ALS, Santos SHS and De-Paula AMB: Body mass index and the visceral adipose tissue expression of IL- 6 and TNF-alpha are associated with the morphological severity of non-alcoholic fatty liver disease in individuals with class III obesity. Obes Res Clin Pract 12 (Suppl 2): S1-S8, 2018. 
59. Vida M, Gavito AL, Pavón FJ, Bautista D, Serrano A, Suarez J, Arrabal S, Decara J, Romero-Cuevas M, Rodríguez de Fonseca F and Baixeras E: Chronic administration of recombinant IL-6 upregulates lipogenic enzyme expression and aggravates high-fat-diet-induced steatosis in IL-6-deficient mice. Dis Model Mech 8: 721-731, 2015.

60. Romeo S, Huang-Doran I, Baroni MG and Kotronen A: Unravelling the pathogenesis of fatty liver disease: Patatin-like phospholipase domain-containing 3 protein. Curr Opin Lipidol 21: 247-252, 2010.

61. Romeo S, Kozlitina J, Xing C, Pertsemlidis A, Cox D, Pennacchio LA, Boerwinkle E, Cohen JC and Hobbs HH: Genetic variation in PNPLA3 confers susceptibility to nonalcoholic fatty liver disease. Nat Genet 40: 1461-1465, 2008

62. Wang X, Liu Z, Wang K, Wang Z, Sun X, Zhong L, Deng G Song G, Sun B, Peng Z and Liu W: Additive effects of the risk alleles of PNPLA3 and TM6SF2 on non-alcoholic fatty liver disease (NAFLD) in a Chinese population. Front Genet 7: 140, 2016.

63. Sookoian S and Pirola CJ: Meta-analysis of the influence of I148M variant of patatin-like phospholipase domain containing 3 gene (PNPLA3) on the susceptibility and histological severity of nonalcoholic fatty liver disease. Hepatology 53: 1883-1894, 2011

64. Aragonès G, Auguet T, Armengol S, Berlanga A, Guiu-Jurado E, Aguilar C, Martínez S, Sabench F, Porras JA, Ruiz MD, et al: PNPLA3 expression is related to liver steatosis in morbidly obese women with non-alcoholic fatty liver disease. Int J Mol Sci 17 630, 2016.

65. Zhang L, You W, Zhang H, Peng R, Zhu Q, Yao A, Li X, Zhou Y, Wang X, Pu L and Wu J: PNPLA3 polymorphisms (rs738409) and non-alcoholic fatty liver disease risk and related phenotypes: A meta-analysis. J Gastroenterol Hepatol 30: 821-829, 2015.

66. Rossi C, Marzano V, Consalvo A, Zucchelli M, Levi Mortera S, Casagrande V, Mavilio M, Sacchetta P, Federici M, Menghini R, et al: Proteomic and metabolomic characterization of streptozotocin-induced diabetic nephropathy in TIMP3-deficient mice. Acta Diabetol 55: 121-129, 2018.

67. Pawlak M, Lefebvre P and Staels B: Molecular mechanism of PPAR $\alpha$ action and its impact on lipid metabolism, inflammation and fibrosis in non-alcoholic fatty liver disease. J Hepatol 62 : $720-733,2015$

68. Manzano León N, Torres $\mathrm{N}$ and Tovar AR: Mechanism of action of sterol regulatory element binding proteins (SREBPs) in cholesterol and fatty-acid biosynthesis. Rev Invest Clin 54: 145-153, 2002 (In Spanish)

69. Ziamajidi N, Khaghani S, Hassanzadeh G, Vardasbi S, Ahmadian S, Nowrouzi A, Ghaffari SM and Abdirad A: Amelioration by chicory seed extract of diabetes- and oleic acid-induced non-alcoholic fatty liver disease (NAFLD)/non-alcoholic steatohepatitis (NASH) via modulation of PPAR $\alpha$ and SREBP-1. Food Chem Toxicol 58: 198-209, 2013.

70. Park HS, Jeon BH, Woo SH, Leem J, Jang JE, Cho MS, Park IS Lee KU and Koh EH: Time-dependent changes in lipid metabolism in mice with methionine choline deficiency-induced fatty liver disease. Mol Cells 32: 571-577, 2011.

71. Van Rooyen DM and Farrell GC: SREBP-2: A link between insulin resistance, hepatic cholesterol, and inflammation in NASH. J Gastroenterol Hepatol 26: 789-792, 2011.

72. Adolph TE, Grander C, Grabherr F and Tilg H: Adipokines and non-alcoholic fatty liver Disease: Multiple interactions. Int J Mol Sci 18: 1649, 2017

73. Gatselis NK, Ntaios G, Makaritsis K and Dalekos GN Adiponectin: A key playmaker adipocytokine in non-alcoholic fatty liver disease. Clin Exp Med 14: 121-131, 2014.

74. Ahmad A, Ali T, Kim MW, Khan A, Jo MH, Rehman SU, Khan MS, Abid NB, Khan M, Ullah R, et al: Adiponectin homolog novel osmotin protects obesity/diabetes-induced NAFLD by upregulating AdipoRs/PPAR $\alpha$ signaling in ob/ob and $\mathrm{db} / \mathrm{db}$ transgenic mouse models. Metabolism 90: 31-43, 2019.

75. Navekar R, Rafraf M, Ghaffari A, Asghari-Jafarabadi M and Khoshbaten M: Turmeric supplementation improves serum glucose indices and leptin levels in patients with nonalcoholic fatty liver diseases. J Am Coll Nutr 36: 261-267, 2017.

76. Perfield JW II, Ortinau LC, Pickering RT, Ruebel ML, Meers GM and Rector RS: Altered hepatic lipid metabolism contributes to nonalcoholic fatty liver disease in leptin-deficient $\mathrm{Ob} / \mathrm{Ob}$ mice. J Obes 2013: 296537, 2013.

77. Zelber-Sagi S, Lotan R, Shlomai A, Webb M, Harrari G, Buch A, Nitzan Kaluski D, Halpern Z and Oren R: Predictors for incidence and remission of NAFLD in the general population during a seven-year prospective follow-up. J Hepatol 56: 1145-1151, 2012.
78. Polyzos SA, Aronis KN, Kountouras J, Raptis DD, Vasiloglou MF and Mantzoros CS: Circulating leptin in non-alcoholic fatty liver disease: A systematic review and meta-analysis. Diabetologia 59: 30-43, 2016.

79. Polyzos SA, Kountouras J and Mantzoros CS: Leptin in nonalcoholic fatty liver disease: A narrative review. Metabolism 64 60-78, 2015.

80. Liu Y, Qiu DK and Ma X: Liver X receptors bridge hepatic lipid metabolism and inflammation. J Dig Dis 13: 69-74, 2012.

81. Rong X, Albert CJ, Hong C, Duerr MA, Chamberlain BT, Tarling EJ, Ito A, Gao J, Wang B, Edwards PA, et al: LXRs regulate ER stress and inflammation through dynamic modulation of membrane phospholipid composition. Cell Metab 18: 685-697, 2013.

82. Lima-Cabello E, García-Mediavilla MV, Miquilena-Colina ME, Vargas-Castrillón J,Lozano-Rodríguez T,Fernández-Bermejo M, Olcoz JL, González-Gallego J, García-Monzón C and Sánchez-Campos S: Enhanced expression of pro-inflammatory mediators and liver X-receptor-regulated lipogenic genes in non-alcoholic fatty liver disease and hepatitis C. Clin Sci (Lond) 120: 239-250, 2011.

83. Ni M, Zhang B, Zhao J, Feng Q, Peng J, Hu Y and Zhao Y: Biological mechanisms and related natural modulators of liver X receptor in nonalcoholic fatty liver disease. Biomed Pharmacother 113: 108778, 2019.

84. Tsai TH, Chen E, Li L, Saha P, Lee HJ, Huang LS, Shelness GS, Chan L and Chang BHJ: The constitutive lipid droplet protein PLIN2 regulates autophagy in liver. Autophagy 13: 1130-1144, 2017.

85. Imai Y, Boyle S, Varela GM, Caron E, Yin X, Dhir R, Dhir R, Graham MJ and Ahima RS: Effects of perilipin 2 antisense oligonucleotide treatment on hepatic lipid metabolism and gene expression. Physiol Genomics 44: 1125-1131, 2012.

86. Sherriff JL, O'Sullivan TA, Properzi C, Oddo J-L and Adams LA: Choline, its potential role in nonalcoholic fatty liver disease, and the case for human and bacterial genes. Adv Nutr 7: 5-13, 2016.

87. Michel V, Singh RK and Bakovic M: The impact of choline availability on muscle lipid metabolism. Food Funct 2: 53-62, 2011.

88. Suk KT and Kim DJ: Gut microbiota: Novel therapeutic target for nonalcoholic fatty liver disease. Expert Rev Gastroenterol Hepatol 13: 193-204, 2019.

89. Pradhan-Sundd T, Vats R, Russell JO, Singh S, Michael AA, Molina L, Kakar S, Cornuet P, Poddar M, Watkins SC, et al: Dysregulated bile transporters and impaired tight junctions during chronic liver injury in mice. Gastroenterology 155 : 1218-1232.e24, 2018.

90. Sookoian S, Castaño GO, Scian R, Fernández Gianotti T, Dopazo H, Rohr C, Gaj G, San Martino J, Sevic I, Flichman D and Pirola CJ: Serum aminotransferases in nonalcoholic fatty liver disease are a signature of liver metabolic perturbations at the amino acid and Krebs cycle level. Am J Clin Nutr 103: 422-434, 2016.

91. Lake AD, Novak P, Shipkova P, Aranibar N, Robertson DG, Reily MD, Lehman-McKeeman LD, Vaillancourt RR and Cherrington NJ: Branched chain amino acid metabolism profiles in progressive human nonalcoholic fatty liver disease. Amino Acids 47: 603-615, 2015.

92. Cheng S, Wiklund P, Autio R, Borra R, Ojanen X, Xu L, Törmäkangas $\mathrm{T}$ and Alen $\mathrm{M}$ : Adipose tissue dysfunction and altered systemic amino acid metabolism are associated with non-alcoholic fatty liver disease. PLoS One 10: e0138889, 2015.

93. Haufe S, Witt H, Engeli S, Kaminski J, Utz W, Fuhrmann JC, Rein D, Schulz-Menger J, Luft FC, Boschmann M and Jordan J: Branched-chain and aromatic amino acids, insulin resistance and liver specific ectopic fat storage in overweight to obese subjects. Nutr Metab Cardiovasc Dis 26: 637-642, 2016.

94. van den Berg EH, Flores-Guerrero JL, Gruppen EG, de Borst MH, Wolak-Dinsmore J, Connelly MA, Bakker SJL and Dullaart RPF: Non-alcoholic fatty liver disease and risk of incident type 2 diabetes: Role of circulating branched-chain amino acids. Nutrients 11: 705, 2019.

95. Zhang F, Zhao S, Yan W, Xia Y, Chen X, Wang W, Zhang J, Gao C, Peng C, Yan F, et al: Branched chain amino acids cause liver injury in obese/diabetic mice by promoting adipocyte lipolysis and inhibiting hepatic autophagy. EBioMedicine 13: $157-167,2016$.

96. Li T, Geng L, Chen X, Miskowiec M, Li X and Dong B: Branched-chain amino acids alleviate nonalcoholic steatohepatitis in rats. Appl Physiol Nutr Metab 38: 836-843, 2013. 
97. Ra SG, Miyazaki T, Kojima R, Komine S, Ishikura K, Kawanaka K, Honda A, Matsuzaki Y and Ohmori H: Effect of BCAA supplement timing on exercise-induced muscle soreness and damage: A pilot placebo-controlled double-blind study J Sports Med Phys Fitness 58: 1582-1591, 2018.

98.Zarfeshani A, Ngo S and Sheppard AM: Leucine alters hepatic glucose/lipid homeostasis via the myostatin-AMP-activated protein kinase pathway-potential implications for nonalcoholic fatty liver disease. Clin Epigenetics 6: 27, 2014

99. Celinski K, Konturek PC, Slomka M, Cichoz-Lach H, Brzozowski T, Konturek SJ and Korolczuk A: Effects of treatment with melatonin and tryptophan on liver enzymes, parameters of fat metabolism and plasma levels of cytokines in patients with non-alcoholic fatty liver disease-14 months follow up. J Physiol Pharmacol 65: 75-82, 2014.

100. Chen Y, Li C, Liu L, Guo F, Li S, Huang L, Sun C and Feng R: Serum metabonomics of NAFLD plus T2DM based on liquid chromatography-mass spectrometry. Clin Biochem 49: 962-966, 2016

101. Jin R, Banton S, Tran VT, Konomi JV, Li S, Jones DP and Vos MB: Amino acid metabolism is altered in adolescents with nonalcoholic fatty liver disease-an untargeted, high resolution metabolomics study. J Pediatr 172: 14-19.e5, 2016.

102. Gaggini M, Carli F, Rosso C, Buzzigoli E, Marietti M, Della Latta V, Ciociaro D, Abate ML, Gambino R, Cassader M, et al Altered amino acid concentrations in NAFLD: Impact of obesity and insulin resistance. Hepatology 67: 145-158, 2018.

103. Stojanović M, Todorović D, Sćepanović L, Mitrović D, Borozan S, Dragutinović V, Labudović-Borović M, Krstić D, Čolović $\mathrm{M}$ and Djuric D: Subchronic methionine load induces oxidative stress and provokes biochemical and histological changes in the rat liver tissue. Mol Cell Biochem 448: 43-50, 2018

104. Dai H, Wang W, Tang X, Chen R, Chen Z, Lu Y and Yuan H: Association between homocysteine and non-alcoholic fatty live disease in Chinese adults: A cross-sectional study. Nutr J 15 $102,2016$.

105. Pacana T, Cazanave S, Verdianelli A, Patel V, Min HK, Mirshahi F, Quinlivan E and Sanyal AJ: Dysregulated hepatic methionine metabolism drives homocysteine elevation in diet-induced nonalcoholic fatty liver disease. PLoS One 10 e0136822, 2015

106. de Carvalho SC, Muniz MT, Siqueira MD, Siqueira ER, Gomes AV, Silva KA, Bezerra LC, D'Almeida V, de Oliveira CP and Pereira LM: Plasmatic higher levels of homocysteine in non-alcoholic fatty liver disease (NAFLD). Nutr J 12: 37, 2013.

107. Abu-Serie MM, El-Gamal BA, El-Kersh MA and El-Saadani MA: Investigation into the antioxidant role of arginine in the treatment and the protection for intralipid-induced non-alcoholic steatohepatitis. Lipids Health Dis 14: 128, 2015.

108. Dogru T, Genc H, Tapan S, Ercin CN, Ors F, Aslan F, Kara M Sertoglu E, Bagci S, Kurt I and Sonmez A: Elevated asymmetric dimethylarginine in plasma: An early marker for endothelia dysfunction in non-alcoholic fatty liver disease? Diabetes Res Clin Pract 96: 47-52, 2012.

109. Voloshin I, Hahn-Obercyger M, Anavi S and Tirosh O L-arginine conjugates of bile acids-a possible treatment for non-alcoholic fatty liver disease. Lipids Health Dis 13: 69, 2014.

110. Chalasani N, Younossi Z, Lavine JE, Diehl AM, Brunt EM, Cusi K, Charlton Mand Sanyal AJ: American Gastroenterological Association; American Association for the Study of Liver Diseases; American College of Gastroenterologyh: The diagnosis and management of non-alcoholic fatty liver disease: Practice guideline by the American gastroenterological association, American association for the study of liver diseases, and American college of gastroenterology. Gastroenterology 142 $1592-1609,2012$.

111. Chiang JYL and Ferrell JM: Bile acid metabolism in liver pathobiology. Gene Expr 18: 71-87, 2018.

112. Tanaka N, Matsubara T, Krausz KW, Patterson AD and Gonzalez FJ: Disruption of phospholipid and bile acid homeostasis in mice with nonalcoholic steatohepatitis. Hepatology 56 $118-129,2012$

113. Ferslew BC, Johnston CK, Tsakalozou E, Bridges AS, Paine MF Jia W, Stewart PW, Barritt AS IV and Brouwer KL: Altered morphine glucuronide and bile acid disposition in patients with nonalcoholic steatohepatitis. Clin Pharmacol Ther 97: 419-427, 2015.
114. Lake AD, Novak P, Shipkova P, Aranibar N, Robertson D, Reily MD, Lu Z, Lehman-McKeeman LD and Cherrington NJ: Decreased hepatotoxic bile acid composition and altered synthesis in progressive human nonalcoholic fatty liver disease. Toxicol Appl Pharmacol 268: 132-140, 2013.

115. Evans RM and Mangelsdorf DJ: Nuclear receptors, RXR, and the big bang. Cell 157: 255-266, 2014

116. Okushin K, Tsutsumi T, Enooku K, Fujinaga H, Kado A, Shibahara J, Fukayama M, Moriya K, Yotsuyanagi $\mathrm{H}$ and Koike K: The intrahepatic expression levels of bile acid transporters are inversely correlated with the histological progression of nonalcoholic fatty liver disease. J Gastroenterol 51: 808-818, 2016.

117. Schiöth HB, Boström A, Murphy SK, Erhart W, Hampe J, Moylan C and Mwinyi J: A targeted analysis reveals relevant shifts in the methylation and transcription of genes responsible for bile acid homeostasis and drug metabolism in non-alcoholic fatty liver disease. BMC Genomics 17: 462, 2016.

118. Kim SG, Kim BK, Kim K and Fang S: Bile acid nuclear receptor farnesoid $\mathrm{X}$ receptor: Therapeutic target for nonalcoholic fatty liver disease. Endocrinol Metab (Seoul) 31: 500-504, 2016.

119. Martin IV, Schmitt J, Minkenberg A, Mertens JC, Stieger B, Mullhaupt B and Geier A: Bile acid retention and activation of endogenous hepatic farnesoid-X-receptor in the pathogenesis of fatty liver disease in ob/ob-mice. Biol Chem 391: 1441-1449, 2010.

120. Toyoda Y, Takada T, Yamanashi $\mathrm{Y}$ and Suzuki $\mathrm{H}$ : Pathophysiological importance of bile cholesterol reabsorption: Hepatic NPC1L1-exacerbated steatosis and decreasing VLDL-TG secretion in mice fed a high-fat diet. Lipids Health Dis 18: 234, 2019.

121. Yoshida M: Novel role of NPC1L1 in the regulation of hepatic metabolism: Potential contribution of ezetimibe in NAFLD/NASH treatment. Curr Vasc Pharmacol 9: 121-123, 2011.

122. Nomura M, Ishii H, Kawakami A and Yoshida M: Inhibition of hepatic Niemann-Pick C1-like 1 improves hepatic insulin resistance. Am J Physiol Endocrinol Metab 297: E1030-E1038, 2009.

123. Aguilar-Olivos NE, Carrillo-Córdova D, Oria-Hernández J, Sánchez-Valle V, Ponciano-Rodríguez G, Ramírez-Jaramillo M, Chablé-Montero F, Chávez-Tapia NC, Uribe $M$ and Méndez-Sánchez N: The nuclear receptor FXR, but not LXR, up-regulates bile acid transporter expression in non-alcoholic fatty liver disease. Ann Hepatol 14: 487-493, 2015.

124. Bechmann LP, Kocabayoglu P, Sowa JP, Sydor S, Best J, Schlattjan M, Beilfuss A, Schmitt J, Hannivoort RA, Kilicarslan A, et al: Free fatty acids repress small heterodimer partner (SHP) activation and adiponectin counteracts bile acid-induced liver injury in superobese patients with nonalcoholic steatohepatitis. Hepatology 57: 1394-1406, 2013

125. Rao A, Kosters A, Mells JE, Zhang W, Setchell KD, Amanso AM, Wynn GM, Xu T, Keller BT, Yin H, et al: Inhibition of ileal bile acid uptake protects against nonalcoholic fatty liver disease in high-fat diet-fed mice. Sci Transl Med 8: 357ra122, 2016.

126. Chassaing B, Etienne-Mesmin L and Gewirtz AT: Microbiota-liver axis in hepatic disease. Hepatology 59: 328-339, 2014

127. Houghton D, Stewart CJ, Day CP and Trenell M: Gut microbiota and lifestyle interventions in NAFLD. Int J Mol Sci 17: 447, 2016.

128. Castaño-Rodríguez N, Mitchell HM and Kaakoush NO: NAFLD, Helicobacter species and the intestinal microbiome. Best Pract Res Clin Gastroenterol 31: 657-668, 2017.

129. Chen YM, Liu Y, Zhou RF, Chen XL, Wang C, Tan XY, Wang LJ, Zheng RD, Zhang HW, Ling WH, et al: Associations of gut-flora-dependent metabolite trimethylamine-N-oxide, betaine and choline with non-alcoholic fatty liver disease in adults. Sci Rep 6: 19076, 2016

130. Koeth RA, Wang Z, Levison BS, Buffa JA, Org E, Sheehy BT, Britt EB, Fu X, Wu Y, Li L, et al: Intestinal microbiota metabolism of L-carnitine, a nutrient in red meat, promotes atherosclerosis. Nat Med 19: 576-585, 2013.

131. Datz C, Müller E and Aigner E: Iron overload and non-alcoholic fatty liver disease. Minerva Endocrinol 42: 173-183, 2017.

132. Moya D, Baker SS, Liu W, Garrick M, Kozielski R, Baker RD and Zhu L: Novel pathway for iron deficiency in pediatric non-alcoholic steatohepatitis. Clin Nutr 34: 549-556, 2015 
133. Tsuchiya H, Ashla AA, Hoshikawa Y, Matsumi Y, Kanki K, Enjoji M, Momosaki S, Nakamuta M, Taketomi A, Maehara $\mathrm{Y}$, et al: Iron state in association with retinoid metabolism in non-alcoholic fatty liver disease. Hepatol Res 40: 1227-1238, 2010.

134. Handa P, Morgan-Stevenson V, Maliken BD, Nelson JE, Washington S, Westerman M, Yeh MM and Kowdley KV: Iron overload results in hepatic oxidative stress, immune cell activation, and hepatocellular ballooning injury, leading to nonalcoholic steatohepatitis in genetically obese mice. Am J Physiol Gastrointest Liver Physiol 310: G117-G127, 2016.

135. O'Brien J and Powell LW: Non-alcoholic fatty liver disease: Is iron relevant? Hepatol Int 6: 332-341, 2012.

136. Tan TC, Crawford DH, Jaskowski LA, Subramaniam VN, Clouston AD, Crane DI, Bridle KR, Anderson GJ and Fletcher LM: Excess iron modulates endoplasmic reticulum stress-associated pathways in a mouse model of alcohol and high-fat diet-induced liver injury. Lab Invest 93: 1295-1312, 2013.

137. Fujita $\mathrm{N}$ and Takei Y: Iron overload in nonalcoholic steatohepatitis. Adv Clin Chem 55: 105-132, 2011

138. Uysal S, Armutcu F, Aydogan T, Akin K, Ikizek M and Yigitoglu MR: Some inflammatory cytokine levels, iron metabolism and oxidan stress markers in subjects with nonalcoholic steatohepatitis. Clin Biochem 44: 1375-1379, 2011.

139. Aigner E, Weiss G and Datz C: Dysregulation of iron and copper homeostasis in nonalcoholic fatty liver. World J Hepatol 7: $177-188,2015$

140. Hagström H, Nasr P, Bottai M, Ekstedt M, Kechagias S, Hultcrantz R and Stål P: Elevated serum ferritin is associated with increased mortality in non-alcoholic fatty liver disease after 16 years of follow-up. Liver Int 36: 1688-1695, 2016.

141. Ghamarchehreh ME, Jonaidi-Jafari N, Bigdeli M, Khedmat H and Saburi A: Iron status and metabolic syndrome in patients with non-alcoholic fatty liver disease. Middle East J Dig Dis 8 31-38, 2016.
142. Iwasa M, Hara N, Iwata K, Ishidome M, Sugimoto R, Tanaka H, Fujita N, Kobayashi Y and Takei Y: Restriction of calorie and iron intake results in reduction of visceral fat and serum alanine aminotransferase and ferritin levels in patients with chronic liver disease. Hepatol Res 40: 1188-1194, 2010.

143. Kowdley KV, Belt P, Wilson LA, Yeh MM, NeuschwanderTetri BA, Chalasani N, Sanyal AJ and Nelson JE; NASH Clinical Research Network: Serum ferritin is an independent predictor of histologic severity and advanced fibrosis in patients with nonalcoholic fatty liver disease. Hepatology 55: 77-85, 2012

144. Valenti L, Dongiovanni P and Fargion S: Diagnostic and therapeutic implications of the association between ferritin level and severity of nonalcoholic fatty liver disease. World J Gastroenterol 18: 3782-3786, 2012.

145. Boga S, Alkim H, Alkim C, Koksal AR, Bayram M, Yilmaz Ozguven MB and Tekin Neijmann S: The relationship of serum hemojuvelin and hepcidin levels with iron overload in nonalcoholic fatty liver disease. J Gastrointestin Liver Dis 24: 293-300, 2015.

146. Tsuchiya H, Ebata Y, Sakabe T, Hama S, Kogure K and Shiota G: High-fat, high-fructose diet induces hepatic iron overload via a hepcidin-independent mechanism prior to the onset of liver steatosis and insulin resistance in mice. Metabolism 62: 62-69, 2013.

147. Valenti L, Swinkels DW, Burdick L, Dongiovanni P, Tjalsma H, Motta BM, Bertelli C, Fatta E, Bignamini D, Rametta R, et al: Serum ferritin levels are associated with vascular damage in patients with nonalcoholic fatty liver disease. Nutr Metab Cardiovasc Dis 21: 568-575, 2011.

This work is licensed under a Creative Commons Attribution-NonCommercial-NoDerivatives 4.0 International (CC BY-NC-ND 4.0) License. 